\title{
Isolated Small Bowel Transplantation in Turkey: A Single Center Experience Running Title: Isolated Small Bowel Transplantation in Turkey
}

\author{
Ismail Sert, M.D. \\ Eyup Kebabci, M.D. \\ Cem Tugmen, M.D.
}

Tepecik Training and Research Hospital, Department of Transplantation and General Surgery, Izmir, Turkey

Masallah Baran, MD, Assc. Prof.

Katip Celebi University, School of Medicine, Department of Pediatric Gastroenterolgy, Izmir, Turkey

Sait Murat Dogan, M.D.

Tepecik Training and Research Hospital,

Department of Transplantation and General Surgery, Izmir, Turkey

Selcuk Kilınc, MD.

Izmir Private Ata Hospital, Deparment of Biochemistry, Izmir, Turkey

Isıl Kose, MD

Sanem Gunturk, MD

Tepecik Training and Research Hospital, Deparment of Anesthesia and Rehabilitation, Izmir, Turkey

Mustafa Soyoz, MD

Katip Celebi University, School of Medicine, Department of Medical Biology, Izmir, Turkey

Tepecik Training and Research Hospital, Department of Immunology, Izmir, Turkey

Mustafa Olmez, M.D.

Cezmi Karaca,M.D.

Tepecik Training and Research Hospital, Department of Transplantation and General Surgery, Izmir, Turkey

doi: 10.19044/esj.2016.v12n12p1 URL:http://dx.doi.org/10.19044/esj.2016.v12n12p1

\begin{abstract}
Background SBTx has become a feasible therapeutic option for patients with irreversible intestinal failure. Increase in the number and in the
\end{abstract}


improvement of the patient and graft survival in SBTx has a slow course when compared to other solid organ transplantation.

Aim The aim of this study is to analyze 25 isolated SBTx performed since 2003 at a single center. It also aims to compare the patient and graft survivals rate during the early (before 2010) and late (after 2010) period.

Materials and Methods Medical charts of 24 patients were analyzed retrospectively. To compare the center's experience during a twelve year period, the results were divided into two groups (before (n:7) and after 2010 $(n: 18))$. At the appropriate time, data were reported as mean \pm standard deviation, median, and range. Kaplan Meier method was used for the survival analysis of the graft and the patients.

Results Median age of the patients was 39 (min 6 months, max: 56 yr). Six of them were in the pediatric age group. Compared to before 2010, graft survival rates increased from $28.1 \%$ to $53.8 \%$ in 3 months, from $28.6 \%$ to $35.9 \%$ in 6 months, and from $14.3 \%$ to $29.9 \%$ in one year after 2010. At the same period, patient survival rate increased from $57.1 \%$ to $72.2 \%$ in 3 months, from $28.6 \%$ to $38.9 \%$ in 6 months, and from $14.3 \%$ to $33.3 \%$ in one year. In the pediatric age group, patient and graft survival rates were $85.7 \%$ in 3 months, $71.4 \%$ in 6 months, and $71.4 \%$ in 1 year.

Conclusion SBTx is an effective treatment choice for selected patients with intestinal failure. Although patient and graft survival rates were improved after 2010 in our center, it was inferior. Patient and graft survival rates in pediatric SBTx are favourable and promising.

Keywords: Small bowel transplantation, isolated small bowel transplantation, intestinal failure, graft survival, patient survival, turkey

\section{Introduction}

Intestinal failure (IF) is defined as the state of the intestinal function which is below the minimum requirement for the absorption of macronutrients, water, and electrolytes (Kaufmann et al., 2015). However, underlying causes of intestinal failure may be divided into three main categories, namely: short bowel syndrome, motility disorders, and primary mucosal disorders (Gupte et al., 2006). The patients with intestinal failure have to be administered Total Parenteral Nutrition (TPN) through the central venous access. Thus, through the help of Total parenteral support, patient's survival rates have increased. On the other hand, TPN have introduced new problems like parenteral nutrition associated liver disease, vascular access problems, and cathater associated life threating blood stream infections (Touloukian et al., 1973). Despite the advancement, contemporary multicenter studies stated that 19-26\% of TPN dependent patients develop severe complications; also, they have indications for Small bowel 
transplantation (SBTx) (Pironi et al., 2011; Squires et al., 2012). In addition, for patients with irreversible intestinal failure, SBTx has become a feasible therapeutic option (Furukawa et al., 1997).

During the past two decades through the technical innovations in surgery, improved postoperative care, achievement of efficient prevention, treatment, and/or control of rejection, and the outcomes of SBTx have been improved (Abu-Elmagd et al., 2001). However, it is still a challenging procedure due to strong organ immunogenity (Ceulemans et al., 2015). Till now, 2887 transplants on 2699 patients have been performed worldwide (Grant et al., 2015). Thus, one year graft failure rate is still high (29\%) for patients who were transplanted since 2000 (Grant et al., 2015). Although, the mortality and morbidity rates of intestinal transplant recipients are similar to permanent TPN patients, the rate of graft failure beyond 1 year is yet to be improved (Grant et al., 2015; Ueno et al., 2011).

At Tepecik training and research hospital, 25 isolated SBTx on 24 patients were performed as at December 2003. In the present study, we reported a single center with twelve years of experience on SBTx.

\section{Materials and Methods}

Medical charts of 24 patients which underwent 25 isolated SBTx since 2003 were analyzed retrospectively. Donor and recipient demographic data which include cold ischemia time, number of HLA mismatch, cause of intestinal failure, blood groups, immunosupressive treatment, acute rejection rates, cause of graft and patient loss, and patient follow-up data were recorded. Therefore, comparing the center's experience (preoperative and postoperative care, ICU, rejection management, etc.) during a twelve year period, the results were divided into two groups (before (n:7) and after 2010 (n:18)). Only isolated SBTx were performed in our center.

\section{Statistical Analysis}

Statistical Package for Social Sciences (SPSS) version 22 (USA) was used for the whole statistical analysis. At the appropriate time, data were reported as mean \pm standard deviation, median, and range. $P$ value of less than 0.05 was considered to be significant. Chi-squared and Fischer Exact tests were performed to compare demographic covariates between groups, when appropriate. Mann-Whitney $\mathrm{U}$ test was used to assess the differences in rank distributions of continuous variables between two groups. Consequently, Kruskal Wallis test was used to compare variables among three different groups. In addition, Kaplan-Meier method was used for the survival analysis of the graft and the patients. 


\section{Results}

Twenty five isolated SBTx were performed for 24 patients since 2003. Thus, all the patients were suffering from life threating complications (vascular access problems, recurrent cathater infections, fungal infections, etc.) due to irreversible intestinal failure. Liver disease (mild fibrosis) associated with Parenteral nutrition was observed in three patients. None of the patients had irreversible intestinal failure. All the patients were under treatment, and were followed up at the hospital prior to the transplantation.

\section{Recipient Characteristics}

The median age of the patients was 39 (min 6 months, max: 56 yr). Fourty eight percent (n:12) of the patients were female. Six of them $(25 \%)$ were in the pediatric age group. However, the main causes of intestinal failure were mesenteric artery thrombosis (83\%, n:15) in adult patients and malrotation (n:2) and waanderburg syndrome(n:2) in pediatric patients. Mean cold ischemia time was $368+115$ min. Median waiting time was 3 months (min 1 day, max: 12 months). Also, retransplantation was performed for only one patient who had graft lost due to chronic rejection in 45 months. Bone marrow mesenchimal stem cell (BMSCs) therapy was introduced to 8 patients (3 pediatric patients) beside SBTx. However, our BMSCs procedure was previously described elsewhere (Dogan et al., 2014).

\section{Donor Characteristics}

All intestinal grafts were recovered from heart beating brain death donors. Median age of the donors was 33 (min: 3 yr, max: $60 \mathrm{yr}$ ). Sixteen of the 25 donors were male. Mean BMI of the donors was $24+3 \mathrm{~kg} / \mathrm{m}^{2}$ (min: 10,4 , max 31.9). Thus, the most common cause of brain death was traumatic/spontaneous subarachnoid bleeding (84\%). Fifty two percent (n:14) of the donors were obtained from regional sharing. Also, median ICU stay was for 3 days (min: 1, max: 12 days).

\section{Immunologic Parameters}

Complement dependent cytotoxicty (CDC) and Flow cytometry cross-match were negative for all patients. Only one patient was introduced to a desentisitation protocol (Intravenous Immunoglobuline + Plashmapherase and rituximab) due to high Panel reactive antibodies (PRA) levels and recurrent cross match positivity (Gondolesi et al., 2006). However, this patient died after one month of transplantation due to refractory acute rejection and sepsis. Blood group compatible intestinal graft was used in three SBTx. The median number of HLA mismatch was 4. 


\section{Surgical Technique}

Before the harvesting, colistin, gentamycin, and fungostatin infusion was introduced via gastric tube into donor's small bowel for the last five cases. In early cases, gastric tube lavage and intragastric antibiotic and antifungal treatment was not introduced. However, we used only the solution from the University of Wisconsin $\left(\mathrm{UW}^{\mathrm{TM}}\right)$ for organ perfusion. Also, only static cold storage technique was used for organ storage.

Median number of previous abdominal operation was three. Eighteen of the patients had ultra-short segment of intestine. Open abdomen was observed for 8 patients prior to transplantation. Ileojejunal graft was used for all adult recipients. Jejunal graft was used for only one pediatric recipient. Colon segment was not used for any recipients. Superior mesenteric artery was anostomosed to infra renal aorta. Thus, superior mesenteric vein anostomosis was performed on infra renal vena cava by end to side fashion. Extension graft was not used. Proximal gastrointestinal continuity was established by jejunoduedenal anostomosis. A simple ostomy was performed for the distal end. Gastrojejunal feeding tube was introduced for enteral support for all patients. In addition, ostomy was taken down the first year after transplantation.

\section{Immunsupression}

Induction treatment contained Rabbit anti-thymocyte globulin (rATG-Fresenius ${ }^{\circledR}$ ) (n: 23,91\%, total dose $10 \mathrm{mg} / \mathrm{kg}$ ) or Basiliximab (n:2, $8.7 \%$, at 0 and 4 days) and steroid (10 mg/kg). Rituximab (375 mg/kg) was used prior to SBTx on the one hypersentisized patient. After transplantation, tacrolimus is used for all patients until the observed bowel movement. Thus, this is followed by oral tacrolimus treatment. Main immunosuppression has an high dose tacrolimus (Prograf TM, 15-20 ng/ml) in the first month period. Maintenance therapy included tacrolimus $(12-15 \mathrm{ng} / \mathrm{ml}$ in first two months and 8-10 ng/ml in following months) and low dose steroid (for 9 months). After two months, sirolimus (n: 23) or everolimus (n:2) (3-8 ng/ml) were added. Immunosuppression protocol for acute cellular rejection (ACR) includes high dose steroid, rATG therapy, and/or intravenous immunoglobulin (IVIG). Besides, we used TNF-blocker (Remicade $^{\circledR}$, Janssen Biotech, Inc.) in one patient with the chronic rejection.

\section{Follow Up and Graft-patient Survival}

Graft monitoring by endoscopy after transplantation by ostomy, twice in the first two weeks than after endoscopic examination, was done periodically for one week interval until the second month.

Median patient follow up was 8 months before 2010, and 11 months after 2010. When SBTx were grouped as before and after 2010, it was seen 
that pediatric transplantations and the use of BMSCs have begun. Therefore, organ retrieving from regional sharing was higher in the second period. There was no statistically significant difference among the two groups. Subsequently, Table 1 summarizes the comparison of the patient and donor demographic data among two groups.

When compared to before 2010, graft survival rates were increased from $28.1 \%$ to $53.8 \%$ in 3 months, from $28.6 \%$ to $35.9 \%$ in 6 months, and from $14.3 \%$ to $29.9 \%$ in one year after 2010 . At the same period, patient's survival was increased from $57.1 \%$ to $72.2 \%$ in 3 months, from $28.6 \%$ to $38.9 \%$ in 6 months, and from $14.3 \%$ to $33.3 \%$ in one year. In the pediatric age group which begun after 2010, patient and graft survival rates were 85.7\% in 3 months, $71.4 \%$ in 6 months, and $71.4 \%$ in 1 year.

\section{Discussion}

Increase in the number and improvement of the patient and graft survival rate in SBTx has a slow course compared to the other solid organ transplantations. The complexity of the management and treatment of acute rejection with a lymphoid rich content, have an important role to play in this situation (Abu-Elmagd et al., 2001). Although due to these difficulties, in the last two decades, SBTx has been a feasible treatment of choice for patients with irreversible intestinal failure. However, they suffer from life threating complications associated with total parenteral nutrition.

2887 SBTx on 2699 patients were performed in 82 transplant centers between 1985 and February 2013 according to the Intestinal Transplant Registry (ITR) (Grant et al., 2015). Furthermore, seventy six percent of the world SBTx activity was carried out in North America. Most of the SBTx were performed in few centers and less than half of the transplant centers are currently active. Between 2009 and 2013, the number of transplant centers that performed at least one SBTx were 47. Twenty seven transplant centers were closed due to the SBTx programs during the same period (Grant et al., 2015). Unfortunately, except for North America, the SBTx activity has not increased. Also, low volume SBTx in many developed countries needs more attention (Celemans et al., 2015; Di Benedetto et al., 2005; Pascher et al., 2005; Soin et al., 2014). Therefore, this present study is important owing to the report of the experience of a small volume transplant centers in a developing country. Our Center is the most active. Therefore, there is only one pediatric SBTx center in Turkey, and the number of SBTx have been increasing since the last two years.

Previously, lopushinsky et al suggested that when SBTx is indispensable, it should be performed before the development of the irreversible liver failure (Lopushinsky et al., 2007). According to Intestinal transplant registry report, isolated SBTx without liver is recently in the trend 
of increase (Grant et al., 2015). In our series, three of the patients were suffering from reversible liver failure. Thus, none of the patients had any complications associated with the liver failure.

Furthermore, it was shown that waiting at home is related to better graft survival rates in SBTx (Grant et al., 2015). Seventy two percent of the patients that underwent SBTx between 2001 and 2011 were waiting at home. Most especially, South America and Asia transplant centers performed SBTx for sicker patients (63\% and $79 \%$ of the patients were at home prior to transplantation) (Grant et al., 2015). In Turkey, there is no well-established active home parenteral nutrition program for patients with intestinal failure. In our series, all the patients were under treatment at the hospital prior to SBTX.

The main cause of the patient's lost in SBTx is sepsis (\%50). Acute rejection (13\%) and cardiovascular events (8\%) are other cause of patient's lost in SBTx (Grant et al., 2015). The risk of bacterial infection in the first year was reported as 90-100 \% previously. Thus, the risk of fungal infection is reported as 30-50\% at the same period (Mangus et al., 2013). Mucosal barrier impairment which induced bacterial translocation during acute rejection episode was accused for the increase in severity and the frequency of sepsis (Middleten et al., 2005). The relation of sepsis and acute rejection is seen as the most important cause of patient's and graft lost. In the present study, sepsis was the most common cause of patient lost as well (\%.47, N:9).

The diagnosis and the treatment of the acute rejection is still an unresolved problem in SBTx (A Hilmi et al., 2013). Between 2005 and 2008, the percentage of SBTx recipients treated for acute rejection is 30-40\% (Mazariegos et al., 2010). Thus, it was reported as $80 \%$ the last year (David et al., 2007). In our series, the rate of acute rejection was $43 \%$ before 2010 , and was 33\% after 2010.

The currently used tools for the diagnosis of the acute rejection in SBTx are clinic findings, endoscopic follow up, and biopsy evaluation (A Hilmi et al., 2013). The first 30 days after SBTx is very significant term for the occurrence of acute rejection (Ceulemans et al., 2015). This situation emphasizes the importance of induction treatment. Recent studies show that the use of anti-thymocyte globulin, anti-interleukin receptor blockers and alemtuzumab, decreases the rate of acute rejection (A Hilmi et al., 2013; Sudan et al., 2014). According to OPTN/SRTR 2011 annual report, 75 \% of the SBTx recipients have introduced the induction treatment (Sudan et al., 2013). In another study that compares the effectiveness of the induction protocols for the prevention of acute rejection, it shows that the use of antilymphocyte globuline reduces the ACR but increases the infection rates (Trevizol et al., 2012). 
According to SRTR data, in 1998, one year graft and patient survival was $52 \%$ and $69 \%$. Thus, these rates became $75 \%$ and $79 \%$ in 2007 , respectively (A Hilmi et al., 2013). When the SRTR intestinal scientific report (between 2012 and 2014) was analyzed, one year graft and patient survival rates were seen at the range of $25 \%$ and $95 \%$ depending on the patient volume (SRTR, 2015). In the present study, one year graft and patient survival rates have been improved after 2010 (from 14.3\% to 29.9\% and from $14.3 \%$ to $33.3 \%$ respectively). Although the results have been improved by the time, graft and patient survival is still inferior compared to SRTR data. Nevertheless, one year graft and patient's survival rates in pediatric patients $(71.4 \%)$ were favourable with the registry data. It seems that the improvement of the survival rates after 2010 is mainly dependent on the better outcomes of pediatric patients.

\section{Conclusion}

In conclusion, SBTx is an effective treatment choice for selected patients with intestinal failure. Although patient and graft survival rates are improved after 2010 in our center, it is still inferior. Patient and graft survival rates in pediatric SBTx are favourable and promising.

\section{References:}

Kaufmann et al. (2015). Management of Intestinal failure. Mİnerve Pediatrica.; 67(4):321-340

Gupte et al. (2006). Current issues in the management of intestinal failure. Arch Dis Child; 91(3): 259-64

Touloukian et al. (1973). Cholestasis associated with long-term parenteral hyperalimentation. Arch Surg; 106:58-62

Pironi et al. (2011). Long term follow up of patients on home parenteral nutrition in Europe: Implications for intestinal transplantation. Gut; 60: 1725

Squires et al. (2012). Natural history of pediatric intestinal failure Consortium. J Pediatr; 161:723-728

Furukawa et al. (1997). Influence of donor criteria on early outcome after intestinal transplantation. Transplant Proc; 29(1-2):690

Abu-Elmagd et al. (2001). Clinical intestinal transplantation: A decade of experience at a single center. Annals of Surgery ; 234(3):404-417

Ceulemans et al. (2015). Belgian multicenter experience with intestinal transplantation. Transp Int ; 28: 1362-70

Grant et al. (2015). Intestinal transplant registry report: global activity and trends. Am J Transplant; 15(1):210-219

Ueno et al. (2011). Current status of intestinal transplantation in Japan. Transplant Proceed.; 43: 2405-7 
Dogan et al. (2014). Mesenchymal stem cell therapy in patients with small bowel transplantation: Single center experience. World J Gastroentrol ; 20(25): 8215-8220

Gondolesi et al. (2006). Pretransplant immunomodulation of highly sensitized small bowel transplant candidates with intravenous immune globuline. Transplantation ;81: 1743-1746

Di Benedetto et al. (2005). Outcome of isolated small bowel transplantation in adults: experience from a single italian center.Minerva Chir ; 60(1): 1-9

Li Y et al. (2014). Sixteen consecutive adult intestinal transplantation: asingle center clinical experience in China. Hepatogastroenterology ; 61(135): 1883-8

Pascher et al. (2005). Clinical results of intestinal and multivisseral transplantation at the Charite, Berlin. A case series. Dtsch Med Wochenschr ;130(8):387-92

Soin et al. (2014). India's first successful intestinal transplant: the road traveled and the lessons learnt. Indian J Gastroenterol ; 33(2): 104-13

Lopushinsky et al. (2007). The optimal timing of intestinal transplantation for children with intestinal failure. A Markov analysis. Ann Surg; 246: 10921099

Mangus et al. (2013). Multivisceral transplantation expanding indications and improving outcomes. J Gastrointest Surg ; 17(1): 179-186

Middleten et al. (2005). The current status of small bowel transplantation in the UK and Internationally. Gut ;54(11) : 1650-57

A Hilmi et al. (2013). Isolated small bowel transplantation outcomes and the impact of immunosupressants: Experience of a single transplant center. World J Transplant; 3(4):127-133

Mazariegos et al. (2010). Intestinal transplantation in the United States,19992008. Am J Transplant ; 10(2):1020-1034

David et al. (2007). Blood citrulline level is an exclusionary marker for significant acute rejection after intestinal transplantation. Transplantation; 84: $1077-1081$

Sudan (2014). The current state of intestine transplantation: Indications, techniques, outcomes and challenges. Am J Transplant. 2014;14: 1976-1984 Trevizol et al. (2012). Intestinal and multivisceral transplantation immunosuppression protocols-Literature review; 44: 2445-2448 http://www.srtr.org/csr/current/Centers/TransplantCenters.aspx?organcode=I $\mathrm{N}$ 
Table Legends

Table 1. Comparison of the patient and donor demographic data among two groups (before and after 2010)

\begin{tabular}{|c|c|c|c|}
\hline & Before 2010 & After 2010 & $P$ value \\
\hline Recipient age (yr) & $37+8$ & $33+18$ & 0.319 \\
\hline $\begin{array}{l}\text { Pediatric cases } \\
\end{array}$ & n: 0 & $\mathrm{n}: 6$ & 0.001 \\
\hline Recipient weight (kg) & $57+14$ & $49+24$ & 0.517 \\
\hline Recipient BMI & $21+0.7$ & $25+7$ & 0.287 \\
\hline $\begin{array}{c}\text { Cause of Intestinal } \\
\text { failure } \\
\text { Mesenteric artery } \\
\text { trombosis } \\
\text { Waanderburg } \\
\text { Syndrome } \\
\text { Malrotation } \\
\text { Crohn disease } \\
\text { Burger disease } \\
\text { Traumatic injury } \\
\text { Surgical complication } \\
\text { Chronic rejection: }\end{array}$ & $\begin{array}{l}\mathrm{n}: 5 \\
\mathrm{n}: 0 \\
\mathrm{n}: 0 \\
\mathrm{n}: 1 \\
\mathrm{n}: 1 \\
\mathrm{n}: 0 \\
\mathrm{n}: 0 \\
\mathrm{n}: 0\end{array}$ & $\begin{array}{c}\mathrm{n}: 11 \\
\mathrm{n}: 2 \\
\mathrm{n}: 2 \\
\mathrm{n}: \\
\mathrm{n}: \\
\mathrm{n}: 1 \\
\mathrm{n}: 1 \\
\mathrm{n}: 1\end{array}$ & 0.444 \\
\hline $\begin{array}{l}\text { Mesenchimal stem cell } \\
\text { infusion }\end{array}$ & n: 0 & n: 8 & 0.001 \\
\hline $\begin{array}{c}\text { Induction Treatment } \\
\text { Basiliximab/ATG }\end{array}$ & n: $2 / 5$ & n: $1 / 17$ & 0.311 \\
\hline $\begin{array}{c}\text { Blood group } \\
\text { Identical/competable }\end{array}$ & n: $6 / 1$ & n: $14 / 4$ & 0.312 \\
\hline Acute Rejection & n: 3 & n: 6 & 0,656 \\
\hline Cold ischemia time & $240+160$ & $396+84$ & 0.053 \\
\hline Duration of operation & $330+64$ & $475+87$ & 0.141 \\
\hline $\begin{array}{c}\text { Donor Center } \\
\text { İzmir/ Regional }\end{array}$ & n: 5/2 & n: 6/12 & 0.008 \\
\hline Waiting time (days) & 20 days & 89 days & 0.333 \\
\hline $\begin{array}{l}\text { Postoperative hospital } \\
\text { stay }\end{array}$ & 52 days & 84 days & 0.386 \\
\hline Donor Age & $32+13$ & $36+16$ & 0.242 \\
\hline $\begin{array}{l}\text { Donor Gender } \\
\text { Woman/Man }\end{array}$ & n: $3 / 4$ & n: $6 / 12$ & 0.854 \\
\hline Donor Weight & $65+7$ & $69+19$ & 0.338 \\
\hline $\begin{array}{l}\text { Cause of Brain Death } \\
\text { Traumatic } \\
\text { /spontaneous Brain } \\
\text { injury } \\
\text { Other }\end{array}$ & $\begin{array}{l}\mathrm{n}: 5 \\
\mathrm{n}: 2\end{array}$ & $\begin{array}{c}\mathrm{n}: 15 \\
\mathrm{n}: 3\end{array}$ & 0.773 \\
\hline ICU Stay (day) & $2.5+0.7$ & $3.5+2.9$ & 0.918 \\
\hline $\begin{array}{c}\text { Cardiac arrest } \\
\text { (Yes/No) }\end{array}$ & $2 / 5$ & $3 / 15$ & 0.484 \\
\hline $\begin{array}{c}\text { Cause of Recipient } \\
\text { death } \\
\text { Sepsis } \\
\text { Acute rejection } \\
\text { Pulmonary Embolia } \\
\text { PTLD } \\
\text { Graft thrombosis }\end{array}$ & $\begin{array}{l}\mathrm{n}: 3 \\
\mathrm{n}: 0 \\
\mathrm{n}: 1 \\
\mathrm{n}: 0 \\
\mathrm{n}: 2\end{array}$ & $\begin{array}{l}\mathrm{n}: 6 \\
\mathrm{n}: 2 \\
\mathrm{n}: 1 \\
\mathrm{n}: 1 \\
\mathrm{n}: 3\end{array}$ & 0.632 \\
\hline
\end{tabular}

